\title{
A pheromone bouquet controls the reproductive behaviour of the male shore crab, Carcinus maenas
}

\author{
Nichola Fletcher $\cdot$ John A. Terschak $\cdot$ Helga D. Bartels-Hardege $\cdot$ \\ Ralf Bublitz $\cdot$ Paula Schirrmacher $\cdot$ Jorg D. Hardege $\mathbb{C}$
}

Received: 30 May 2021/Accepted: 4 December 2021/Published online: 24 December 2021

(C) The Author(s) 2021

\begin{abstract}
The reproduction of many brachyuran crustaceans involves the formation of mating pairs often around the time of the female moult with attraction of a sexual partner and mating behaviour controlled by sex pheromones. In shore crabs, Carcinus maenas, females produce sex pheromones that are released in the urine. High Performance Liquid Chromatography analysis (HPLC) of female urine shows that the pheromone, identified as the nucleotide uridine diphosphate (UDP), elutes as an unresolved peak with structurally related nucleotides. We examined female urine samples over the moult cycle and detected UDP as well as uridine triphosphate (UTP). Bioassays were conducted to establish the possibility of a blend of nucleotides forming a sex pheromone bouquet in $C$. maenas. Whilst UDP induced the male
\end{abstract}

Handling Editor: Olivier P. Thomas

Supplementary Information The online version contains supplementary material available at https://doi.org/10.1007/ s10452-021-09930-w.

N. Fletcher · H. D. Bartels-Hardege .

R. Bublitz · P. Schirrmacher · J. D. Hardege $(\bowtie)$

Department of Biological and Marine Sciences,

University of Hull, Hull HU6 7RX, UK

e-mail: j.d.hardege@hull.ac.uk

J. A. Terschak

Yorkshire Marine Research Centre, The Old Harbour Master's Office, Harbour Road, Bridlington YO15 2NR, UK mate guarding behaviour (cradling), a mixture of the two nucleotides at a ratio of 4:1 UDP:UTP elicited an even stronger mating response than either UDP or UTP individually. The urine concentration and composition of these nucleotides changes over the moult period pre and post ecdysis, providing evidence that a pheromone bouquet composition is not always constant. The change of the bouquet is related to the physiological state of the sender, here the moult cycle. Our study unravels the functionality of reactionspecific molecules in a pheromone bouquet. Whilst UDP is the mating signal, UTP acts as an attractant and combined they maximise the reproductive response. The use of bouquets provides species-specificity, potentially enabling reproductive isolation of sympatric species, and contains valuable information on the physiological state of the sender.

Keywords Carcinus maenas - Shore crabs . Pheromone bouquet variability $\cdot$ Reproductive isolation

\section{Introduction}

Animal behaviours are often instigated by complex sensory signals that are associated with speciesspecific life situations. These include numerous key behavioural functions like feeding, predator-prey 
interactions, reproduction and communication in a social context, all of which can be coordinated by olfactory cues and chemoreception (Wyatt 2014). The complexity of signals to which an organism is exposed in the marine environment requires the development of mechanisms to discriminate between the different elements of signals, for example to coordinate their reproductive behaviour (Derby et al. 1996). Amongst the various forms of signalling, chemical communication plays a large role but is the least understood (Wyatt 2009). Chemical signals that mediate reproductive behaviours are usually species-specific methods of communication, which can be achieved by using blends or mixtures. Sex pheromones are often bouquets of structurally similar compounds (Wyatt 2014) albeit few have been described in marine invertebrates. Many insects, particularly moths, use a blend of compounds in a precise, fixed ratio as both species- and population-specific sex pheromones (Cardé et al. 1977; Löfstedt 1993). The nuptial spawning behaviour in two species of marine polychaete, Platynereis dumerilii and Nereis succinea, is mediated by the release of a ketone, 5-methyl-3heptanone in different species-specific concentrations (Hardege et al. 1998) whilst the release of male gametes is coordinated via species specific cues, uric acid (Hardege et al. 1998) and cysteinyl-glutathione (Zeeck et al. 1998a, b). Lepidoptera pheromone bouquets show the same compounds being used in hundreds of species with specific blends as well as environmental timing providing reproductive isolation (Rasmussen et al. 1996). Other aquatic examples for pheromone blends include goldfish (Carassius auratus, Sorensen 1992; Sorensen et al. 1998) and brown algae, where different algae use selected compounds from within these bouquets as their own speciesspecific cues for gamete activation and attraction. The role of other compounds in the mixtures remains unclear but could include deception of competing species or simply form a relict of the biosynthetic pathway for their production that is shared between the different brown algae (see Maier and Müller 1986 for review). Pheromone blends could have evolved for multiple purposes (Byers 2005); apart from making a species reproductively isolated, they could serve as long- and short-range signals, with different parts of the blend having different roles, especially when complex behaviours are controlled (Christensen et al. 1989).
Crustacean pheromones have been widely researched but only in recent years have their chemical compositions been characterised (Breithaupt and Thiel 2011). The identification of the primary sex pheromone in the shore crab has been established as the nucleotide uridine diphosphate (UDP) (Hardege et al. 2011). This sex pheromone is released by the female, predominantly in the urine leading up to and during the moulting stage (ecdysis). Excreted as a byproduct of chitin biosynthesis, the female sex pheromone attracts the male leading to courtship (Hardege et al. 2002, 2011). The male mating behaviour is induced via the release of female sex pheromones which initially attract the male to a female. Males then enter a stereotyped pair formation, with the male exploring the softness of the female carapace and proceeding to cradling the receptive female. This step can be initiated pre- and continued post-moult and also post-mating in what is known as mate guarding. A male can repeatedly respond to this chemical signal, with dominant males having numerous reproduction events with receptive females over the course of the mating season (Van der Meeren 1994). Competitive mate choice has been shown in various brachyuran crabs (Christy 1987). Losers of male-male aggressive interactions though are less likely to respond to UDP and conditioned water containing the female pheromones, and even when responding they require significantly longer before engaging in mating behaviour (Fletcher and Hardege 2009).

There is evidence for heterospecificity in the use of UDP and related nucleotides as the female sex pheromone in a number of other crustaceans (Bublitz et al. 2008), potentially leading to cross-species attraction and conflict between species. Evolution of species specific pheromones is complex as the use of specific chemicals raises demands on exclusivity of signal biosynthesis and reception. A reproductive event that leads to avoidance in space and time (premating reproductive isolation) should therefore play an important role in such environments where multiple species reproduce. There are examples for pre-mating reproductive isolation in the marine environment, this includes polychaetes such as the lugworm Arenicola marina and Nereidid ragworms (Bentley and Pacey 1992; Hardege et al. 1998) and in crustaceans the formation of pre-mating pairs is widespread (Christy 1987). 
Shore crabs, as omnivorous intertidal predators, have in the past decades become a major global invader (Yamada 2001) that impact fisheries, aquaculture and ecosystems, disrupting ecological networks leading to loss of biodiversity (Grosholz and Ruiz 1996), and substantial economic impacts (Molnar et al. 2008). This study explores the pheromones detectable in female shore crab urine to explore potential synergistic effects of the compounds forming the odour bouquet, potentially useful for improving population management strategies. Since pheromone production is linked to the female moult, we also investigate the composition of the pheromone bouquet over time, in pre and post ecdysis, as male mate-choice is likely to be based on the quality of the chemical signal mixture.

\section{Materials and methods}

All crabs (Carcinus maenas) were collected at monthly intervals during spring tides over the summer months (June-September) from the intertidal zone in pre-copula pairs near Forder, Cornwall, UK and transported to Hull University where they were kept in a temperature-controlled room simulating summer conditions throughout the study $(15: 9 \mathrm{~h}$ light:dark, $17 \pm 2{ }^{\circ} \mathrm{C}$ ). Unpaired crabs occurred in the cultures after the pairs split up post-mating and at the time of the female hardening out her new carapace. These were maintained in communal holding tanks $(76 \times 64 \times 25 \mathrm{~cm})$ supplied with circulating seawater (32-34\%o), while pre-copula pairs were kept in smaller individual holding tanks $(30 \times 20 \times 20 \mathrm{~cm})$ each filtered with its own Mini-Aqua-Flow Filter pump. All crabs were fed on mussel (Mytilus edulis) flesh three times a week. Tanks were checked daily for pre-copula pairs and moulting females. Urine was collected daily from individual females from 5 days prior to 10 days post-moult by immobilising them on a plastic board with rubber bands and the third maxillipeds were temporarily restrained. The urine was collected from the opening of the antennal opercula as described by Bamber and Naylor (1996) using a micropipette attached to an Eppendorf vial. The urine from each crab was passed through a cellulose sterile filter (12,000 RPM, centrifuge tube filters, Costar) and frozen at $-20{ }^{\circ} \mathrm{C}$. The females were returned to their individual tanks with their male partner. After completion of the behavioural assays, all crabs were released to their site of origin as part of the monthly sampling trips. All experiments were undertaken following ethical approval through the University of Hull ethics committee (ref UO20). To reduce stress in experiments (Wilson et al. 2021), the crabs handling was minimised and kept the same in all experiments including the controls to ensure uniformity of any handling impacts between treatments.

The HPLC was an Agilent 1100 system with a quaternary pump, degasser, $100 \mu \mathrm{L}$ loop autosampler, temperature-controlled column compartment, diode array and fluorescence detectors, and a fraction collector, all controlled with the Agilent ChemStation software (Rev. A.10.01). A Phenomenex Synergi Fusion RP column $(4.6 \mathrm{~mm} \times 250 \mathrm{~mm})$ with a C18 guard column was used for the separation using an isocratic mobile phase $\left(0.2 \mathrm{M} \mathrm{KH_{2 }} \mathrm{PO}_{4}, \mathrm{pH} 5.5\right.$, $1 \mathrm{~mL} \mathrm{~min}{ }^{-1}$ ) with a column temperature of $28{ }^{\circ} \mathrm{C}$. The diode array detector was set to scan between 200 and $300 \mathrm{~nm}$ and the injection volume was $100 \mu \mathrm{L}$. To determine UDP and UTP levels in pre- and post-moult females, urine was purified and pooled daily from 3 females for 5 days prior to and 10 days after moulting. This was because the volume of urine that could be obtained varied and was too low to enable injection of $0.1 \mathrm{ml}$ per sample from a single female. Before injection onto the HPLC, large urinary proteins were removed by passing the urine sample through a $10 \mathrm{kDa}$ cellulose centrifugal filter (Amicon; Microcon YM10) subsequently the filtrate was further fractionated by passing it through a $3 \mathrm{kDa}$ cellulose centrifugal filter (Amicon; Microcon YM3). Both the filtrate and the filtrand (retained material) were separately injected and compared with nucleotide standards: UMP (uridine monophosphate), UDP (uridine diphosphate), UTP (uridine triphosphate), uridine, UDPglucose, GMP (guanosine monophosphate), GDP (guanosine diphosphate), GTP (guanosine triphosphate), AMP (adenosine monophosphate), ADP (adenosine diphosphate) and ATP (adenosine triphosphate). All chemicals were obtained from Sigma-Aldrich. Each nucleotide standard was prepared in purified water at a concentration of $10^{-5} \mathrm{~mol} /$ L. The retention times and maximum absorbances in the spectra (200-300 nm) were compared with those of the urine samples. Reporting of chromatograms were done at $268 \mathrm{~nm}$ to reflect specificity towards nucleotides. Partially, resolved peaks were de- 
convoluted using Agilent ChemStation algorithms utilising multiple wavelength spectral absorbances from the diode array detector. The method was confirmed with selected samples using LC-MS. HPLC data showing peak areas for dilution curves of synthetic standards of the nucleotides were used to calibrate the peak areas of the compounds detected in the samples (Hardege et al. 2011). Original data and calibration curve can be found in supplementary material.

Only pre-copula males were used for the behavioural assays that were adapted from Hardege et al. (2002). For this, a pseudo-female model was made using a sponge and screws, all washed with alcohol prior to assembly. The screws were pushed through the sponge giving it a 'crab-like' form. The stimulus (uridine nucleotides) in the bioassays were prepared in the following ratios, using synthetic compounds, at concentration $10^{-4} \mathrm{~mol} / \mathrm{L}: 100 \%$ UDP, 4:1, 3:2, 1:1, 2:3, 1:4, UDP:UTP, 100\% UTP. Individual male crabs (carapace width: $65 \pm 5 \mathrm{~mm}$ ) were placed in static tanks (size-30 $\times 20 \times 20 \mathrm{~cm}$ ) with approximately $10 \mathrm{~cm}$ depth of seawater (32\%) at ambient temperature $\left(16^{\circ} \mathrm{C}\right)$, screened from visual disturbance, and left to acclimate for $30 \mathrm{~min}$. The pseudo-female was first saturated with seawater, added to the opposite end of the tank from the test animal and $1 \mathrm{~mL}$ of the stimulus was pipetted into the sponge by inserting the pipette tip into the sponge in situ. The crabs were visually monitored and scored for their reproductive behaviours. Each crab was only used once to eliminate any possibility of habituation occurring.

This assay procedure was repeated for each of the uridine nucleotide ratios $(N=18)$. As a control, the sponge was treated without any stimulus $(N=18)$. The male's behaviour was graded as described by Hardege et al. (2002) with the cradling stance as the only response considered a full sexual response. Grades used were as follows: $0=$ no movement; $1=$ raised up onto pereopods $2-4 ; 2=$ lifting of the chelipeds to a $90^{\circ}$ angle from the carapace and on occasions lifting of pereopod $5 ; 3=$ movement in a searching motion towards the pseudo-female; 4 = touching of the sponge with the chelipeds; 5 = cradling behaviour, also described as mate guarding behaviour, and males often attempting to turn the female to force mating. These grades were then transferred into percentages of animals that displayed the highest ranked behaviour. The data were analysed using the statistical software $\mathrm{R}$ (version 4.0.2, R Core Team 2020). The responses to the different nucleotide ratios were compared in chi-squared tests for trends in proportions.

To examine whether UDP and UTP is also attractive for males over distance, causing them to move towards a female or its odour, we used a choice chamber flume measuring $2 \mathrm{~m} \times 0.50 \mathrm{~m}$ with a water depth of $29 \mathrm{~cm}$ as described in Hardege et al. (2011). A flow velocity of $40 \mathrm{~cm} \mathrm{~min}^{-1}$ was used. Pheromone stimulus addition (UTP and UDP at $10^{-4} \mathrm{~mol} / \mathrm{L}$ ) was controlled via a Masterflex $\mathrm{L} / \mathrm{S}$ peristaltic pump at a rate of $0.5 \mathrm{~mL} \mathrm{~min}^{-1}$ and the cue injection side randomised Individual male crabs randomly selected from the main culture system $(N=15)$ were placed in a holding chamber within the flume and left to acclimatise for at least $1 \mathrm{~h}$. Once the divider to the main flume was released, the crab's behaviour was observed and recorded via video for an experimental period of $15 \mathrm{~min}$. When crabs moved towards the currents carrying the odour cues the choice of arm by the crab was chosen as parameter. For this to be deemed a response, the crab had to pass into the final $20 \mathrm{~cm}$ of the arm selected within the 15 min experimental time. Preliminary studies showed that in this type of flume crabs once the crabs moved into an arm of the olfactometer very rarely move away again so that the crab reaching the end of the arm was chosen as the experimental endpoint. Data was analysed using the statistical software $\mathrm{R}$ (version 4.0.2, $\mathrm{R}$ core Team 2020). To determine the preference for a chemical cue, the proportion of animals choosing the different stimuli were compared against a 0.5 proportion in an exact binomial test.

\section{Results}

After injection of $100 \mu \mathrm{L}$ of purified female urine, four distinct peaks appeared in the HPLC chromatogram after $3.3,4.8,5.6$ and $8.15 \mathrm{~min}$, of which only the double peak at $3.3 \mathrm{~min}$ had biological activity. Coinjection of $20 \mu \mathrm{L}$ of the synthetic nucleotides $\left(10^{-5} \mathrm{~mol} / \mathrm{L}\right)$ UMP, UDP, UTP, UDP-Glucose, Uridine, GMP, GDP, GTP, AMP, ADP and ATP (as described by Hardege et al. 2011) showed that only two (Fig. 1a) match the retention times and UV spectra of the urine derived peaks: UDP at $3.3 \mathrm{~min}$ 


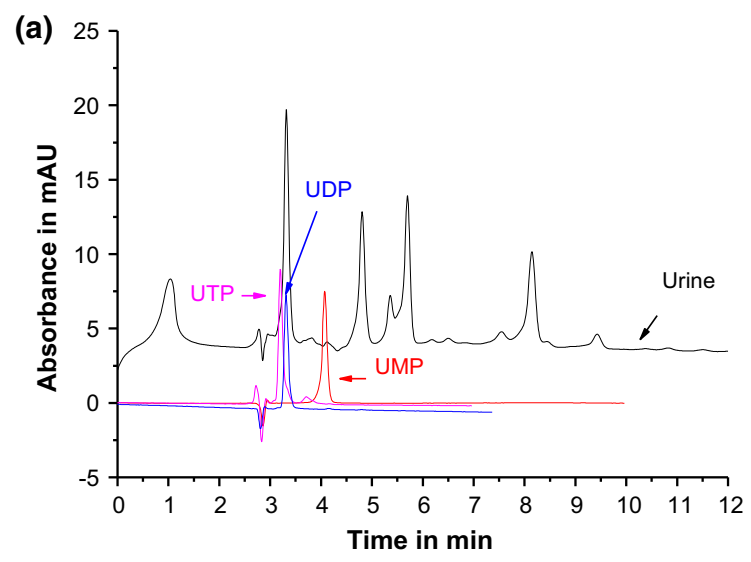

(b)

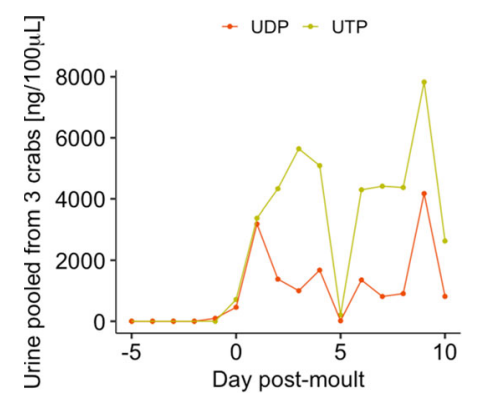

Fig. 1 a Chromatogram of HPLC analysis: $100 \mu \mathrm{L}$ female urine ( 2 days before moult) on Phenomenex RP Fusion column with $0.2 \mathrm{M} \mathrm{KH}_{2} \mathrm{PO}_{4}$ buffer (pH 5.5) at $1 \mathrm{~mL} \mathrm{~min}^{-1}$; overlaid with a chromatogram of HPLC analysis with $20 \mu \mathrm{L}$ nucleotide standards $\left(10^{-5} \mathrm{M}\right)$ : UMP (uridine monophosphate), UDP (uridine diphosphate) and UTP (uridine triphosphate). b Urine levels of UDP (uridine diphosphate) and UTP (uridine triphosphate) in female shore crabs pre- ( $n=5$ samples, urine from 3 females pooled for each sample) and post moult ( $n=10$ samples, urine from 3 females pooled for each sample) in $\mathrm{ng} /$ $100 \mu 1$

$\left(\lambda_{\max }=262 \mathrm{~nm}\right) \quad$ and $\quad$ UTP at $3.2 \mathrm{~min}$ $\left(\lambda_{\text {max }}=262 \mathrm{~nm}\right)$.

Urine samples taken daily from 5 days before to 10 days after the female moult show a radical increase in UDP and UTP levels over time. Very little UTP (below HPLC detection threshold of $58 \mathrm{ng} / 100 \mu \mathrm{L}$, $n=5$ ) was detected in female urine before they moulted. The level of UDP in female urine was up to $95 \mathrm{ng} / 100 \mu \mathrm{L}$ before moulting, but most urine samples were below detection threshold of $62.5 \mathrm{ng} / 100 \mu \mathrm{L}$ urine $(n=5)$. During moult and within 1 day postmoult a surge in UDP levels in the urine occurred, leading to a median of $1000.5 \mathrm{ng} / 100 \mu \mathrm{L}$ female urine (IQR $715.0 \mathrm{ng} / 100 \mu \mathrm{L}$ urine, $n=10$ ) over the 10 days post moult. Similarly, UTP levels increased drastically but simultaneously showed large fluctuation over time (median $4331.7 \mathrm{ng} / 100 \mu \mathrm{L}$ urine, IQR $1746.8 \mathrm{ng} / 100$ $\mu \mathrm{L}, n=10)$ with all post-moult samples containing both nucleotides, UDP and UTP (Fig. 1b). The ratios between UDP and UTP in urine varied between days and samples (post-moult median 3.2:1, IQR 2.7) but always showed higher levels of UTP than UDP.

Since the ratios of the two nucleotides variy between samples and over the moult we exposed male shorecrabs to a range of synthetic UDP and UTP ratios to examine which is the most potentially bioactive ratio. Figure $2 \mathrm{a}$ shows that most nucleotide ratios, with the exception of UDP 3:2 UTP and UDP 1:1 UTP,

\section{(a) $\quad \square$ cradling/mating $\square$ touching with chelipeds}

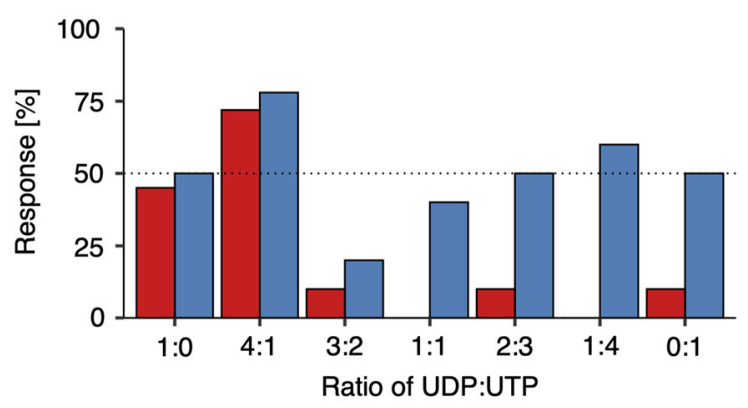

(b) $\square$ UDP $\square$ UTP $\square$ seawater

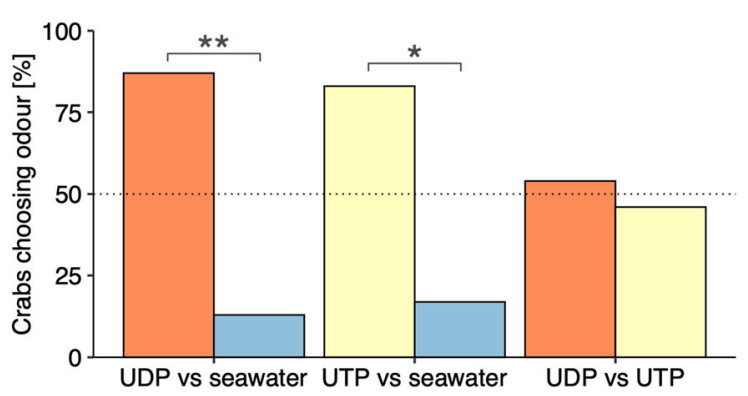

Fig. 2 a Crabs eliciting touching of pseudo-female and cradling, as a full sexual response, in response to different pheromone ratios (uridine diphosphate (UDP) and uridine triphosphate (UTP) in summer conditions. Whilst there is no significant trend in the behavioural response of touching with chelipeds (blue), the cradling response (red) shows a significant trend across the ratios of UDP:UTP $(n=18$, Chi-squared test of trend in proportions, $\chi^{2}=18.6, d f=1, p<0.0001$ ), with higher UDP contents eliciting a stronger response. b Percentage of male Carcinus maenas that choose between uridine diphosphate (UDP), uridine triphosphate (UTP) and seawater during the summer reproductive season. Values given as number of crabs responding, $n=15$. orange $=$ UDP. yellow $=$ UTP. blue $=$ seawater. Asterisks indicate significant difference in choice according to exact binomial test, $* p<0.05, * * p<0.01$ ) 
elicit a behavioural response in at least half of the individuals, indicated by touching of the pseudofemale with the chelipeds. There is no statistically significant trend for the seven pheromone ratios tested for touching of the pseudo-female $\left(\chi^{2}=0.004, d f=1\right.$, $p=0.95)$. Initial touching behaviour did not progress to the full reproductive behavioural response of 'cradling' for all instances. Whilst UTP alone also induced cheliped touching, our results indicate that cradling behaviour is induced in male crabs exposed to nucleotide ratios with higher UDP levels (Fig. 2a). However, adding a small proportion of UTP to UDP clearly increases the behavioural response of male crabs. The 4:1 UDP:UTP mixture induces a 1.6 times higher rate of cradling response and cheliped touching as compared to UDP alone. The trend in cradling response over the pheromone ratio is statistically highly significant $\left(\chi^{2}=18.6, d f=1, p<0.0001\right)$ and decreases with increasing proportion of UTP.

During the summer reproductive season, $100 \%$ of male crabs responded to the UDP stimulus in the flume experiments (see also Hardege et al. 2011) by moving from the holding chamber towards the stimulus source (attraction), whereas male crabs showed $80 \%$ response rate to UTP. Figure $2 b$ shows that of the animals that reacted to the cue, male crabs have a significant preference for UDP over the seawater control (exact binomial test, 0.5 proportion, $P=0.007$ ) and likewise choose UTP over the seawater control (exact binomial test, 0.5 proportion, $p=0.04$ ). However, when male Carcinus maenas are given a choice between the two nucleotides UDP and UTP, no significant difference can be seen (exact binomial test, 0.5 proportion, $p=1)$.

\section{Discussion}

The female moult is the prime time for mating in many crustacean species, the shedding of the female carapace and her subsequent soft state allows for copulation. Aquatic examples of identified pheromone bouquets are increasing, and include fish, such as goldfish (Poling et al. 2001), Nereidid polychaetes (Hardege 1999; Zeeck et al. 1998a, b) and lugworms (Hardege and Bentley 1997). In Nereidid polychaetes and fish, the cues produced can be directly linked to the physiological state of the sender, here maturation (Hardege 1999). To date, the sex pheromone of $C$. maenas, the moult specific biomarker NAGL $(N$ acetylglucosamine-1,5-lactone), that occurs in both helmet crabs (Yano et al. 2016) and blue crabs (Kamio et al. 2014) and induces mating behaviour, and 9-octadecene-amide (Oleamide), the main component of the contact pheromone cue blend in hermaphroditic shrimp, Lysmata boggessi (Zhang et al. 2011) represent the few crustacean sex pheromones that have been established, although headway has also been made in hermit crabs (Okamura et al. 2017). Most of these compounds are linked to the production of chitin at the time of moult and function as moult biomarker (Yano et al. 2016) making species specificity of such cues a challenge. The main component of the sex pheromone blend in Carcinus maenas has been previously identified as uridine diphosphate (UDP), which is found amongst a range of nucleotides in the urine of pre- and post-moult females (Hardege et al. 2011). This reflects the importance of males to detect pre-moult females as shown in a range of brachyuran crabs (Yamamura 1987; Christy 1987, review by Breithaupt and Thiel 2011), but also raises the question whether males can distinguish between pre- and post-moult and with it pre- and post-mated females. Previous HPLC analysis of female urine samples pre and post-ecdysis showed a double peak on RP18 columns near $3.3 \mathrm{~min}$, the retention time of female pheromone (Hardege et al. 2002), indicating the existence of two chemically similar compounds in the peak. Our HPLC analysis of female urine shows the presence of both UDP and UTP in post-moult female urine.

UDP is produced in significant quantities during the last step of the chitin biosynthesis pathway when UDP- $N$-acetylglucosamine is converted into chitin (Merzendorfer and Zimoch 2003). This involves the conversion of uridine triphosphate (UTP) to UDP, potentially resulting in excretion of both in post-moult urine forming a pheromone blend, also called 'bouquet'. Little is known about stability of bouquet ratios and cue quantities released especially when a behaviour occurs repeatedly over a period of days. The female's carapace only starts to harden after 8-14 days and the chitin biosynthesis changes as the moulting stage progresses. Bamber and Naylor (1996) found that post-moult pheromone release (using male attraction as a proxy) in C. maenas increases to its maximum between 3 and 5 days post ecdysis which fits the sharp increase of UTP and UDP in the female urine (see Fig. 1b). During the conversion of $N$ - 
acetylglucosamine-1-phosphate into chitin (Merzendorfer and Zimoch 2003), UTP is used and releases energy, and eventually leaves the chitin biosynthesis scheme as UDP (Mansencal 1999). Indeed, in our analysis of pooled urine from three females each day post moult shows that the ratio of the two nucleotides varies between days (median UDP 1:3.2 UTP, IQR $2.7, n=30$ females, 10 days). Females pre-ecdysis are expected to have low chitin biosynthesis activity whilst those at the beginning of the hardening out process (after ecdysis) should show high levels of chitin biosynthesis. As such, females may excrete different ratios of the two nucleotides pre and post moult. Very low levels of UTP are detectable (below HPLC quantification limit) pre-moult and UDP levels are also low $\left(2.4 \times 10^{-6} \mathrm{~mol} / \mathrm{L}\right)$, but above the behavioural response threshold of $10^{-6} \mathrm{~mol} / \mathrm{L}$ for male crabs as described by Hardege et al. (2011). The significantly higher levels $\left(10^{-5}-10^{-4} \mathrm{~mol} / \mathrm{L}\right)$ for both, UDP and UTP post moult ensure male response even given the dilution effects of releasing urine into the environment.

The variability of the pheromone bouquet indicates that the message associated with the chemical signal may also change over time. We hypothesise that for female shore crabs, pre-moult attraction of a mating partner may dominate, whilst around the moult the induction of the mating behaviour and mating stance are a priority for the sender. Post-mating females should attract or keep males for mate guarding and protection from predators and cannibalism. Ekerholm and Hallberg (2005) demonstrated that female crabs are not simply passive during mating but actively approach males so the olfactory cue interplay between the sexes may be even more complex than currently elucidated, with receivers of cues able to make informed choices upon the physiological status and quality of an individual as potential mating partner. We conclude that the variability in odour profiles may foster informed decision making, the exact details of which require future studies.

Whilst the variable pheromone bouquet might reflect the variable behavioural role of the chemical signal, it is likely to stem from the individual's metabolic fitness or be a result of the duration of time since last urine release. In addition, pheromone release is not limited to urine but shore crabs are known to also release pheromone via the gills (Bamber and Naylor 1996), impacting the cue quantity in the environment.
Qualitative and quantitative stability of pheromone release is a field rarely studied in aquatic organisms but potentially provides the receiver of a message with additional information about a sender's physiological state.

Reproductive behaviour assays using synthetic compounds showed the most bioactive nucleotide ratio to induce the cradling/mating reproductive behaviour to be UDP 4:1 UTP (Fig. 2a), whilst still eliciting high levels of attractiveness by containing both nucleotides. The increased bioactivity of the pheromone blend 4:1 ratio of UDP:UTP potentially maximises the reproductive response of males, albeit all ratios with higher levels of UDP elicit some degree of reproductive cradling. It is important to note that the most bioactive ratio UDP 4:1 UTP for cradling behaviour is not found at all in our female urine samples. The high levels of UTP in female urine show that post-moult female urine is predominantly a male attractant whereby a high quantity of UDP in the urine pheromone bouquet ensures that cradling takes place. Our study confirms that females are chemically attractive to males several days after ecdysis, which fits a 'desperate sender theory' with unmated females' urgency of attracting a male partner increasing dramatically. Hence, the attraction of a male (via UTP) should be the female's initial priority. This is reflected in dramatic increases in their sex pheromone production, before hardening out post ecdysis. If males are able to detect the moulting or reproductive status of the female through the combination of both, UTP and UDP in the pheromone bouquet, as well as the feeding deterrent crustecdysone (20HE), that is only found in pre-moult urine (Hayden et al. 2007) and reduced cannibalism, they could utilise this information to select suitable females, enabling mate choice in the males. Hence, the crab's pheromone bouquet combines the attractiveness of UTP with the induction of a mating response via UDP to attract males over distance and ensure reproduction.

As described by Christensen et al. (1989), pheromone bouquets could have evolved as a mechanism to control multiple components of a complex behaviour. In crustaceans, pheromones are described to function as long range and short range attractants, to elicit typical behavioural displays and to induce copulation behaviour (Zhang et al. 2010), the latter is likely to be controlled also via contact cues (Zhang et al. 2011) that could also play a role in the male shore 
crab decision making as these probe the softness of the female carapace prior to engaging in the cradling behaviour. Pheromone blends are typically described as a well-defined, fixed ratio that is species, reaction, and even population specific (see Wyatt 2014 for review), but our study shows that these blends can vary substantially between individuals and moult stage most likely depending on the physiological state of the sender that produces the signals.

Here, we show that although UDP is the key component of the female Carcinus pheromone system (Hardege et al. 2011), the closely related nucleotide UTP also occurs in female urine, thus suggesting a pheromone bouquet in shore crabs, and potentially other crustacean species (Zhang et al. 2020). Our study shows that the mating response of shore crabs increases 1.6-fold with the addition of a small fraction of UTP to UDP. Moreover, temporal variations in the mixtures within a pheromone bouquet can reflect the moult stage of the sender (female), potentially allowing the receiver of a signal (male) to make decisions about the message conveyed. To our knowledge, this is the first marine invertebrate where evidence exists that changes in the physiological state of a sender reflect directly upon the chemical signal bouquet produced. The optimum ratio and concentrations in pheromone blends eliciting behaviours in laboratory studies are also not necessarily identical with what can be found in urine or real environmental samples, a fact almost entirely overlooked in aquatic chemical ecology. This variability of cues opens future opportunities to study the role of chemical signals in mate choice, size dependent or social status-dependent mating tactics, receptivity, and seasonal responses of the mating partners. Understanding variability in signal production and reception could also have major implications for the practical applications of chemical cues for invasive species control of this global invader and for the development of tools in crustacean management.

Acknowledgements The authors would like to thank the Chemical Ecology group at the University of Hull for their feedback and comments upon the manuscript. This work was supported by NERC (NER/S/C/2004/12985) and by J.W. Aquaculture, Neath, UK. The authors gratefully accept technical support by Victor Sweetez and Margaret Huffee at the Department of Biological and Marine Sciences at Hull University. We are grateful to the students of the department who helped collect shore crabs.
Data availability All data used for Figs. 1 and 2 are available as Supplementary Material.

\section{Declarations}

Conflict of interest There are no conflicts of interest.

Ethical approval All experiments were approved by the University of Hull Ethics Committee under the approvals U020.

Open Access This article is licensed under a Creative Commons Attribution 4.0 International License, which permits use, sharing, adaptation, distribution and reproduction in any medium or format, as long as you give appropriate credit to the original author(s) and the source, provide a link to the Creative Commons licence, and indicate if changes were made. The images or other third party material in this article are included in the article's Creative Commons licence, unless indicated otherwise in a credit line to the material. If material is not included in the article's Creative Commons licence and your intended use is not permitted by statutory regulation or exceeds the permitted use, you will need to obtain permission directly from the copyright holder. To view a copy of this licence, visit http://creativecommons.org/licenses/by/4.0/.

\section{References}

Bamber SD, Naylor E (1996) Chemical communication and behavioural interaction between sexually mature male and female shore crabs (Carcinus maenas). J Mar Biol Ass UK 76:691-699

Bentley MG, Pacey AA (1992) Physiological and environmental control of reproduction in polychaetes. Oceanogr Mar Biol 30:139-148

Breithaupt T, Thiel M (2011) Chemical communications in crustaceans. Springer, Cham

Bublitz R, Sainte-Marie B, Newcomb-Hodgetts C, Fletcher N, Smith M, Hardege JD (2008) Interspecific activity of sex pheromone of the European shore crab (Carcinus maenas). Behav 145:1465-1478

Byers JA (2005) Chemical constraints on the evolution of olfactory communication channels of moths. J Theor Biol 235:199-206

Cardé RT, Cardé AM, Hill AS, Roelofs WL (1977) Sex pheromone Specificity as a reproductive isolating mechanism among the sibling species Archips argyrospilus and $A$. mortuanus and other sympatric tortricine moths (Lepidoptera: Tortricidae). J Chem Ecol 3:71-84

Christensen TA, Mustaparta H, Hildebrand JG (1989) Discrimination of sex pheromone blends in the olfactory system of the moth. Chem Senses 14:463-477

Christy JH (1987) Competitive mating, mate choice and mating associations of brachyuran crabs. Bull Mar Sci 41:177-191

Derby CD, Hutson M, Livermore BA, Lynn WH (1996) Generalization among related complex odorant mixtures and their components: analysis of olfactory reception in the spiny lobster. Physiol Behav 60:67-95 
Ekerholm M, Hallberg E (2005) Primer and short-range releaser pheromone properties of premolt female urine from the shore crab Carcinus maenas. J Chem Ecol 31:1845-1864

Fletcher N, Hardege JD (2009) The cost of conflict: agonistic encounters influence responses to chemical signals in the shore crab, Carcinus maenas. Anim Behav 77:357-361

Grosholz ED, Ruiz GM (1996) Predicting the impact of introduced marine species: lessons from the multiple invasions of the European green crab Carcinus maenas. Biol Conserv 78:59-66

Hardege JD (1999) Nereid polychaetes as model organism for marine chemical ecology: a review. Hydrobiologia 402:145-161

Hardege JD, Bentley MG (1997) Spawning synchrony in Arenicola marina, evidence for a male pheromone. Proc Royal Soc B 264:1041-1047

Hardege JD, Müller CT, Beckmann M, Bartels-Hardege HD (1998) Timing of reproduction in Marine Polychaetes: the role of sex pheromones. Ecoscience 5:395-404

Hardege JD, Jennings A, Hayden D, Müller CT, Pascoe D, Bentley MG, Clare AS (2002) Novel behavioural assay and partial purification of a female-derived sex pheromone in Carcinus maenas. Mar Ecol Progr Ser 244:179-189

Hardege JD, Bartels-Hardege H, Fletcher N, Terschak JA, Harley M, Smith MA, Davidson L, Hayden D, Müller CT, Lorch M, Welham K, Walther K, Bublitz R (2011) Identification of a crustacean female sex pheromone in the shore crab, Carcinus maenas. Mar Ecol Progr Ser 436:177-189

Hayden D, Jennings A, Müller C, Pascoe D, Bublitz R, Webb H, Watkins L, Hardege J (2007) Sex specific mediation of foraging in the shore crab, Carcinus maenas. Horm Behav 52:162-168

Kamio M, Schmidt M, Germann MW, Kubanek J, Derby CD (2014) The smell of moulting: $N$-acetylglucosamino-1,5lactone is a premoult biomarker and candidate component of the courtship pheromone in the urine of the blue crab, Callinectes sapidus'. J Exp Biol 217:1286-1296

Löfstedt C (1993) Moth pheromone genetics and evolution. Phi Trans Royal Soc B 340:167-177

Maier I, Müller D (1986) Sexual pheromones in algae. Biol Bull 170:145-175

Mansencal R (1999) Chitin. In: Mark JE (ed) Polymer data handbook. Oxford University Press, New York, pp 67-69

Merzendorfer H, Zimoch L (2003) Chitin metabolism in insects: structure, function and regulation of chitin synthases and chitinases. J Exp Biol 206:4393-4412

Molnar JL, Gamboa RL, Revenga C, Spalding MD (2008) Assessing the global threat of invasive species to marine biodiversity. Frontiers Ecol Environm 6:458-492

Okamura S, Kawaminami T, Matsuura H, Fusetani N, Goshima S (2017) Behavioral assay and chemical characters of female sex pheromones in the hermit crab Pagarus filholi. J Ethol 35:169-176

Poling KR, Fraser EJ, Sorensen PW (2001) The three steroidal components of the goldfish preovulatory pheromone signal evoke different behaviours in males. Comp Biochem Physiol 129:645-651
R Core Team (2020) R: A language and environment for statistical computing. R Foundation for Statistical Computing, Vienna, Austria. URL https://www.R-project.org/.

Rasmussen LEL, Lee TD, Roelofs WL, Davies GD (1996) Insect pheromones in elephants. Nature 379:684-684

Sorensen PW (1992) Hormonally derived sex pheromones in goldfish: a model for understanding the evolution of sex pheromone systems in fish. Biol Bull 183:173-177

Sorensen PW, Christensen TA, Stacey NE (1998) Discrimination of pheromonal cues in fish: emerging parallels with insects. Curr Opin Neurob 8:458-467

Van der Meeren GI (1994) Sex- and size-dependent mating tactics in a natural population of shore crabs Carcinus maenas. J Anim Ecol 63:307-314

Wilson CH, Nancollas SJ, Rivers ML, Spicer JI, McGaw IJ (2021) Effects of handling during experimental procedures on stress indices in the green shore crab, Carcinus maenas (L). Mar Freshw Behav Phys 54(2):65-85

Wyatt TD (2009) Fifty years of pheromones. Nature 457:262-263

Wyatt TD (2014) Pheromones and animal behaviour. Chemical signals and signatures, 2nd edn. Cambridge University Press, Cambridge

Yamada SB (2001) Global Invader: the European green crab. J Crust Biol 22:694-695

Yamamura N (1987) A model on correlation between precopulatory guarding and short receptivity to copulation. J Theor Biol 127:171-180

Yano H, Kamio M, Nagai H (2016) The molting biomarker metabolite $\mathrm{N}$-acetylglucosamino-1,5-lactone in female urine of the helmet crab Telmessus cheiragonus. Biol Bull 230:143-151

Zeeck E, Müller CT, Beckmann M, Hardege JD, Papke U, Sinnwell V, Schroeder FC, Francke W (1998a) Cysteineglutathione disulfide, the sperm-release pheromone of the marine polychaetes Nereis succinea (Annelida: Polychaeta). Chemoecology 8:33-38

Zeeck E, Harder T, Beckmann M (1998b) Uric acid: the spermrelease pheromone of the Marine Polychaete Platynereis dumerilii. J Chem Ecol 24:13-22

Zhang D, Lin J, Harley M, Hardege JD (2010) Characterization of a sex pheromone in a Simultaneous Hermaphroditic Shrimp, Lysmata wurdemanni (Caridea: Hippolytidae). Mar Biol 157:1-6

Zhang D, Terschak T, Harley M, Lin J, Hardege JD (2011) Contact pheromones in a Simultaneous Hermaphroditic Shrimp Lysmata Boggessi. Plos ONE 6(4):e17720. https:// doi.org/10.1371/journal.pone.0017720

Zhang D, Liu X, Harley M, Hardege JD (2020) Uridine-5'-triphosphate is a candidate component of the soluble sex pheromone bouquet in a marine shrimp, Lysmata wurdemanni. Mar Ecol Progr Ser 640:139-146

Publisher's Note Springer Nature remains neutral with regard to jurisdictional claims in published maps and institutional affiliations. 